\title{
Analyzing Cement Rheological Properties Using Different Additive Schemes at High Pressure and High Temperature Conditions
}

\author{
Khalil Rehman Memon ${ }^{1 a}$, Aftab Ahmed Mahesar ${ }^{1 b}$, Shahzad Ali Baladi ${ }^{1 c}$, \\ Muhannad Talib Sukar ${ }^{2}$
}

RECEIVED ON 18.01.2019, ACCEPTED ON 03.05.2019

\begin{abstract}
The experimental study was conducted on rheological properties in laboratory to measure the integrity of cement slurry. Three samples were used and analyzed at different parameters to check the elasticity of cement slurry. Additives with various concentrations, i.e. silica fume \% BWOC (Present by Weight on Cement) (15, 17, 19 and 21), dispersant \% Wt (Percent Weight) (0.21, 0.26 and 0.31) and additional 1; \% Wt of fluid losscontrol were used to improve the performance of the cement slurry at the temperature of $123^{\circ} \mathrm{C}$. The results have shown that increase in the concentration of dispersants that have caused to decrease in the Plastic Viscosity (PV), Yield Point (YP) and GS (Gel Strength). The rheological properties of cement were improved with the addition of fluid loss control additive in $21 \%$ BWOC (Present by Weight on Cement) silica fume increase the water quantity in cement slurry that improve its durability and to reduce the strength retrogression in High Temperature High Pressure (HTHP) environment. Results were achieved through HTHP OFITE Viscometer (Model 1100).
\end{abstract}

Keywords: Oil Well Cement Slurry, Rheology, Additives.

\section{INTRODUCTION}

The oil well cementing is the process of slurry placement in the annulus space between casing and formation. The primary task of a cement job is to keep the casing in place; prevent corrosion, from saline formation water and avoid the influx of fluid or gases into the annular space and to prevent them from migrating to upper or lower zone as shown in Fig. 1.

The Oil Well Cement (OWC) process involves proper placing and pump-ability of cement slurry of Class-G cement, adding additives, and water into a wellbore, for developing high stability and durability for long term integration of cement slurry [1]. The cement slurry loses its homogeneity at temperature greater than $120^{\circ} \mathrm{C}$. The rheology of cement slurry decreases with increasing temperature in terms of PV and YP, and GS that ultimately the reduce its overall performance like cave in and wash out the holes, fluid migration etc. The improper mixing, low rheology and weak early age compressive strength become great cause of slurry segregation and deterioration of cement slurry. Cement slurry is pumped into the annular space between the borehole and a steel pipe, called a casing intended to produce a conduit from the reservoir to the surface. Stable cement sets in place to support the casing in the hole, to isolate various formations from one another, and to control fluid movement within the well [2]. Typical cement slurry density ranges from 14-17 lb/gal. Certain conditions can be encountered during the well construction process for that

\footnotetext{
${ }^{1}$ Institute of Petroleum and Natural Gas Engineering, Mehran University of Engineering and Technology, Jamshoro, Pakistan. Email: akhalil.memon@faculty.muet.edu.pk (Corresponding Author),

baftab.mehasar@faculty.muet.edu.pk, ${ }^{\text {'shahzad.baladi@faculty.muet.edu.pk }}$

2 UniversityTeknologi Petronas Malaysia. Email: molion25@yahoo.com

This is an open access article published by Mehran University of Engineering and Technology, Jamshoro under CC BY 4.0 International License.
} 


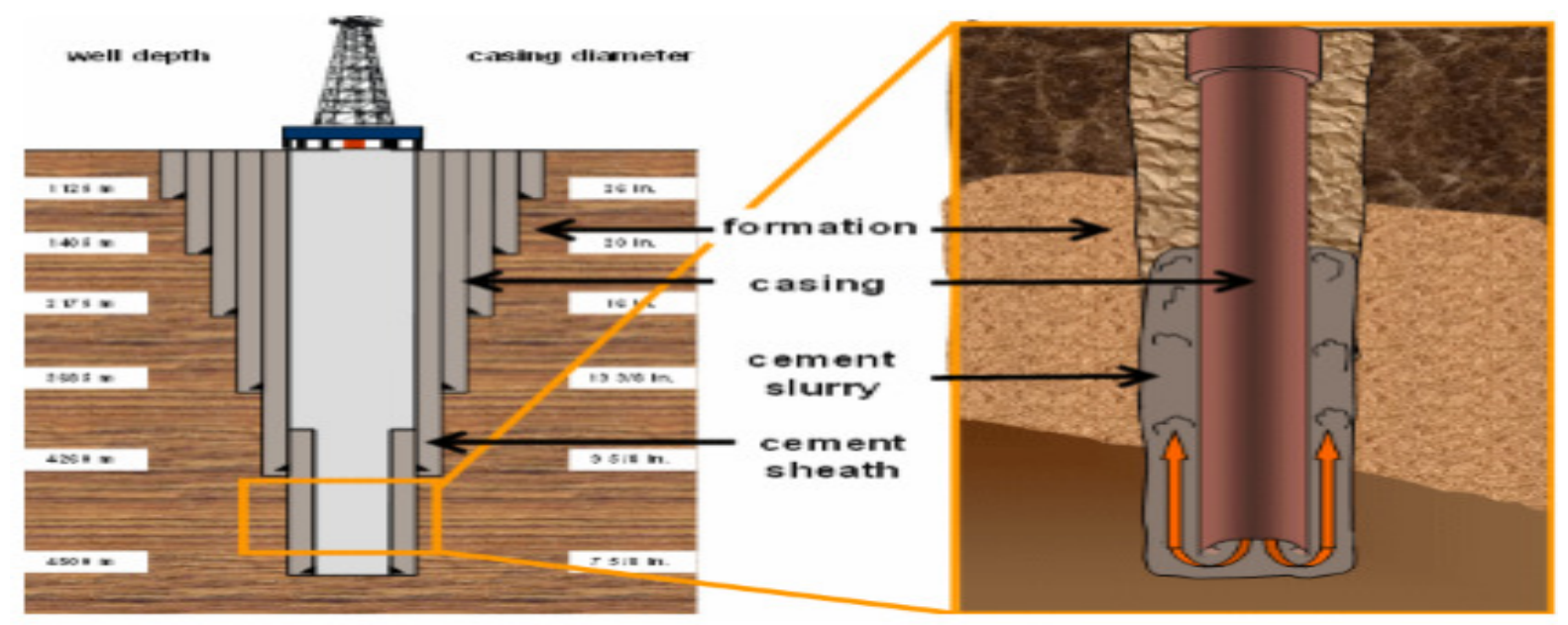

FIG. 1. PLACING THE CEMENT SLURRY BETWEEN CASING AND FORMATION

necessitates to suitable slurry density for particular application of cements with much lower density. Lower density is required to limit hydrostatic pressure exerted on formations through which the wellbore passes in order to prevent from abnormal condition to the formation fracturing and absorb the well fluid [13].

Rheology is the theory of the deformation of materials whose behaviour falls between fluid and solids, further it describes the movement of fluid with relation to the shear stress and shear rate. The design of cement rheology is essential to achieve cement operational success and proper evolution of fluid displacement for optimum cement placement [4].

The rheological properties of cement slurry are very complex and critical to the field performance of setting cement in terms of flow, and workability. The Rheology of cement slurry is strongly influenced by mixing process and material selection, including water-to-cement ratio and temperature [4-5]. Physical measurement of rheological properties of cement slurries with additives evolutions are important tools in cementing jobs to understand properly placing cement slurry without accidents because during the well life, the chances of cement sheath is collapse when uncertainty take place during different well treatment operations e.g. well stimulation and pressure analysis and cement extract jobs. The high temperature and high pressure effects the rheological properties i.e. plastic viscosity, yield point and gel strength. The previous research shown that the accomplish variation of temperature and pressure the rheological properties of cement slurry will change. These events generate thermal and cyclic stresses and cause to change in well profile [6-9].

Rheological study is very useful for petroleum industry to predict the cement slurry stability for zonal isolation, where cements slurry pumped down many feet to the earth for seal vertical limit of casing and formation, for that purpose cement must sustain in pump-able for several hours without any effects during placing at high temperature and pressure. Therefore, chemical additives are used to stable all mechanical properties for proper design cement slurry. A description of flow rate (shear rate) and pressure (shear stress) is related to flow properties of fluid movement $[8,10]$.

The various numerical models were designed to define the relationship among the shear stress and shear rate. Mostly models are described for above relationship based on the Newtonian, Bingham Plastic and Power Law models. All most fluids and cement slurries for drilling cementing are Non-Newtonian fluids and have been treated using a Bingham Plastic or Power Law Type Model [11,12].

Cement rheology is related with various cement properties such as PV, YP, frictional properties, and GS. The rheological properties of cement slurries are very important for simulating pump profile for optimum fluid displacement. These properties assure that the prepared slurry pumped down into the well Mehran University Research Journal of Engineering and Technology, Vol. 39, No. 3, July 2020 [p-ISSN: 0254-7821, e-ISSN: 2413-7219] 
with a minimum pressure drop. It also plays a critical role in mud removal by maintaining the flow regime $[13,14]$.

The slurry properties can be change pressure and temperature with passage of flow regime with addition of multi additive system. This science of rheology is basically used to determine the relationships between shear stress and shear rate in steady laminar flow define Newtonian and non-Newtonian. The durability and firmness of cement slurry will reduce with increase in temperature for the level above a critical temperature. The complex condition will be appeared at approximately temperature above $105^{\circ} \mathrm{C}-115^{\circ} \mathrm{C}$ $[8,10,15,16]$.

The potential and toughness of oil well cement can be considered to achieve confine seal in prevailing reservoir condition. Currently a fact that the strength and durability of the cement slurry reduce with increasing temperature and optimum value was brought to the great attention of the industry. The factors that change the cement rheology such as shape, size, and water cement ratio and composition prepared according to API Standards [17,18].

The YP and PV of the cement slurry usually increase as the cement becomes finer and the performance of cement slurry increases. The rheology of OWC slurries is generally very complex behavior with reference to depth of the well conditions at HTHP environment cement slurries prepared using a number of additives which are usually used for OWC slurries. In addition, the slurry shows different characteristics depending on the combination of the admixture used $[16,18]$.

It has been observed that the flow of the oil well cement slurries follows the Bingham plastic model almost perfectly. The yield value of the cement slurry decreases with an increasing concentration of the dispersant. Glycerine acts as a slurry viscosifier and it has been found that the associated increase in viscosity at the lower shear rates is significantly lower than that at higher shear rates $[11,18,19]$.

The cement shears the thinning characteristics of the Class-G oil well slurry is obtained by using glycerine.
Moreover, the incorporation of sub-micron size polymer latex, and then the replacement of the cement by a polymer powder can lead to a significant reduction in the OWC slurry viscosity. This can improve mix-ability and pump ability $[20,21,22]$. The bottom hole condition will be different by varying the depth. The Class-G cement is very efficient for the completion of the job; due to its efficiency, and its being capable to use additives in the mixing of the cement to sustain the stability of the well. In HTHP conditions of cement slurry reading is approximately $371^{\circ} \mathrm{C}$ and the pressure is 30000 psi. A variety of OWC additives are available to be used according to the requirements of the well. Therefore, numbers of additives are used according to the condition of formation such as accelerators, retarders; extenders and weighting agents are used to increase the performance of cement slurry $[2,17,23,24]$.

\section{EXPERIMENTAL PROCEDURE}

Cement slurry was prepared according to American Petroleum Institute. The mixing method strongly influences on slurry and set cement properties. Cement additives can be wet blended in cement slurry can be used [19].

\subsection{Electronic Balance}

In oil industry electronic balance measuring device to measure the specifications cement slurries and its additives. The procedures of measuring the cement is to dry the cement weight, distilled water and additives in order to prepare cement slurry which meets API standards [19].

\subsection{Electronic Standard 7000 Constant Speed Mixer}

As per electronic standards the appropriate amount of cement and additives by using the Standard 7000 Constant Speed Mixers to mix cement slurry. According to API Standards the $600 \mathrm{ml}$ slurry was prepared and slurry was mixed for 70 seconds. The mixer was operated at 4000 RPM during first 15 seconds in which dry cement was added to water, and this was followed for 55 seconds on that conditions where mixer was set at 12000 RPM followed for 70 seconds. 


\section{RHEOLOGY MEASUREMENT THROUGH OFITE (MODEL 1100) VISCOMTER AT HIGH TEMPERATURE CONDITION}

The OFITE viscometer (Model 1100) was used to measure the rheological properties of the cement slurries according to the API recommended [19]. When conditioning of cement sample was obtained through advanced pressurised viscometer model 1100 with ORCADA software was used to measure the rheological properties of the cement slurries. ORCADA software based simulation which will read rheological properties accurately to determine flow characteristics of fracturing fluids and drilling fluids in term of, plastic viscosity, and yield point, gel strength.

\section{RESULT AND DISCUSSION}

Cement slurry was prepared at 13 PPG (Pound Per Gallon), slurry was prepared with SF concentration of $\% \mathrm{BWOC}(15,17,19$ and 21$)$ and dispersants of $\% \mathrm{Wt}$ $(0.21,0.26$ and 0.31$)$ to measure its properties at $123^{\circ} \mathrm{C}$ using HTHP viscometer to measured GS-10 Min.

\subsection{Plastic Viscosity of 13 PPG Cement Slurry}

In this section, the plastic viscosity of 13 PPG cement slurry was prepared to observe the effect of silica fumes and dispersant at temperature $123^{\circ} \mathrm{C}$ as shown in Fig. 2.

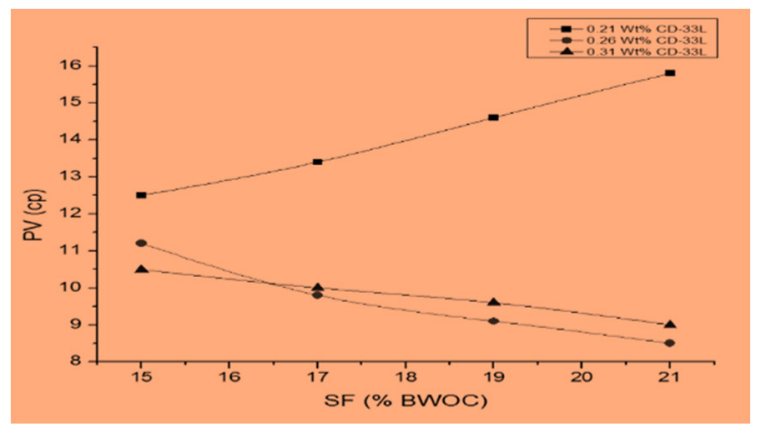

FIG. 2. EFFECTS OF SF AND DISPERSANT ON PV OF 13 PPG SLURRY

The PV of cement slurries was determined using HPHT viscometer. Fig. 2 depicts that $0.21 \% \mathrm{Wt}$ concentration of dispersant the PV of cement slurries was increasing by increasing the concentration of silica fume. The PVs of slurries increased from 12.5-
$15.8 \mathrm{cP}$; by increasing concentration of silica fume 15$21 \%$ BWOC. While the PV decreasing with increasing of silica fume, for both cases of 0.26 and $0.31 \% \mathrm{Wt}$ of dispersant. Silica fume works as a water absorber, usually has a strong tendency to absorb the water in the cement slurry causing an increase in the gel of the slurry to make a strong network of cement and silica fume particles, which cause an increase in PV. While the dispersant has an opposite effect on PV since it is fraction agent PV decreases with the increasing of concentration of dispersant.

When the dispersants concentration increased from $0.21-0.26 \% \mathrm{Wt}$ the PV drops from $12.5-11.2 \mathrm{cP}$, this is due to that the dispersants cause an increase in the inter particle water. So for any percentage of silica fume there is a certain amount of inter particle water could be absorbed but the increase in dispersant concentration cause an excess free inter particle water which cannot absorbed by silica fume causing reduction in PV.

The same effect of dispersant concentration of $0.31 \% \mathrm{Wt}$ can be noticed. We may concluded that cement slurry contained $21 \%$ BWOC silica fume showed $15.8 \mathrm{cP}$ plastic viscosity with $0.21 \% \mathrm{Wt}$ of dispersant. The $\mathrm{PV}$ of $15.8 \mathrm{cP}$ is the appropriate condition of pump-ability and particle sustainability.

\subsection{Yield Point of 13 PPG Cement Slurry}

In this section, the YP of 13 PPG cement slurry was prepared to observe the effect of silica fumes and dispersant at temperature $123^{\circ} \mathrm{C}$ as shown in Fig. 3 .

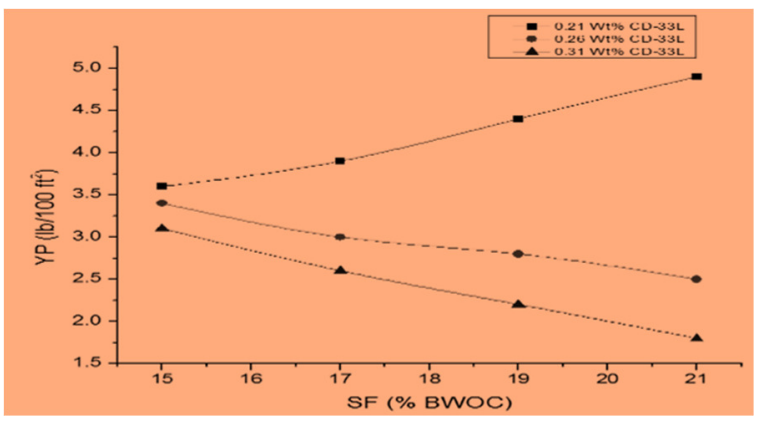

FIG. 3. EFFECTS OF SF AND DISPERSANT ON YP OF 13 PPG SLURRY

The YP of cement slurry is very important property of slurry. The measurement of $\mathrm{YP}$ is important to 
determine the flow ability of slurry. Fig. 3 illustrate that the YP of cement slurries was increasing by increasing concentration of silica fume at $0.21 \% \mathrm{Wt}$ of dispersant; the YP of slurry increased from 3.6-4.9 $\mathrm{lb} / 100 \mathrm{ft}^{2}$ due to the fact that the increase in cause silica fume concentration the more absorption of the water in solution that promote strength increase. As the YP of slurry increases the particles of cement comes close to each other therefore the increased behaviour in YP was observed in all cement slurries of silica fume \%BWOC $(15,17,19$ and 21).

For optimized slurry the YP of slurry should be low in order to improve the flow property of slurry. The YP of slurry was determined by changing the concentration of dispersant. The amount of concentration was increased $0.21,0.26$ and $0.31 \% \mathrm{Wt}$. Likely PV behaviour, the YP of slurries was decreased in all slurries that were used in this work of silica fume \%BWOC $(15,17,19$ and 21) as shown in Fig. 3. The reduction in YP was due to the inter water particle increased. Thereby it increases the spacing among cement particles.

It was noticed that by increasing concentration of silica fume with dispersant then YP of slurry become very low and $1.8 \mathrm{lb} / 100 \mathrm{ft}^{2}$ is not considered appropriate for flow. Therefore, it was concluded that the slurry contains $21 \%$ BWOC of silica fume and $0.21 \% \mathrm{Wt}$ concentration of dispersant is appropriate for rheology.

\subsection{Gel Strength (GS-10 Sec) of 13 PPG Cement Slurry}

In this section the GS of cement slurry at low shear rate after cement has set at rest condition for 10 seconds for examine the strength profile of slurry at temperature $123^{\circ} \mathrm{C}$ using HTHP viscometer.

The GS property is very important for the stability of the cement slurry. The GS of 10 seconds for $13 \mathrm{ppg}$ cement with different \%BWOC silica fume and dispersants \%Wt are shown graphically in Fig. 4. Initially, it was observed that using constant dispersant concentration at $0.21 \% \mathrm{Wt}$ the GS of cement slurry was decreased from $8-5.5 \mathrm{lb} / 100 \mathrm{ft}^{2}$ by increasing silica fume concentration. The reduction in GS of slurry was due to fine particle of silica fume contact to the slurry.
As the concentration of silica fume increased the cohesive force between the cement particles also increased due to this condition decreasing effects shown in Fig. 4. Further this effect found in all slurries that were used in this work by increasing concentration of dispersant the GS of slurry was decreased as observed using 0.26 and $0.31 \% \mathrm{Wt}$ dispersant in cement slurry. The increasing concentration of silica fume reduced the GS that can be observed in Fig. 4.

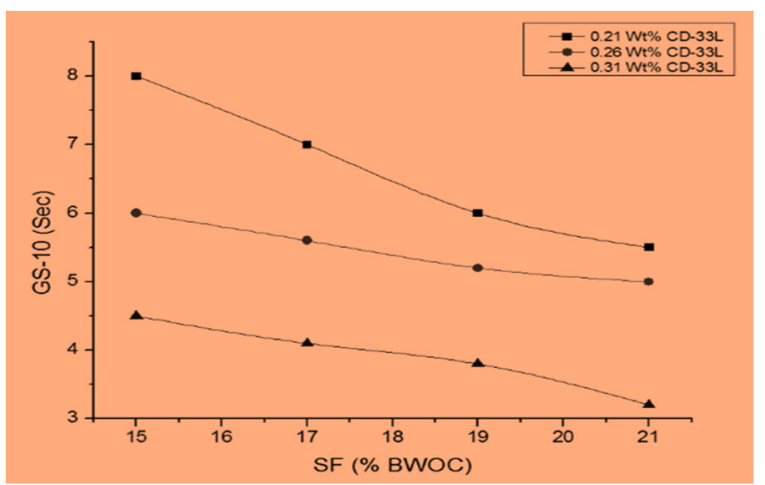

FIG. 4. EFFECTS OF SF AND DISPERSANT ON 10 GS-10 SEC OF 13 PPG SLURRY

\subsection{Gel Strength (GS-10 Min) of 13 PPG Slurry}

Cement slurry was prepared with silica fume concentration of $(15,17,19$ and 21) \%BWOC and dispersants $(0.21,0.26$ and 0.31$) \% \mathrm{Wt}$ to measure its GS (GS-10 Min) at $123^{\circ} \mathrm{C}$ using HTHP viscometer.

The GS at 10 minutes of $13 \mathrm{ppg}$ cement slurries graphically represent in Fig. 5. Fig. 5 depicts that an increasing concentration of silica fume at any concentration of dispersant the gel causes reduction in GS. As the concentration of silica fume increased from

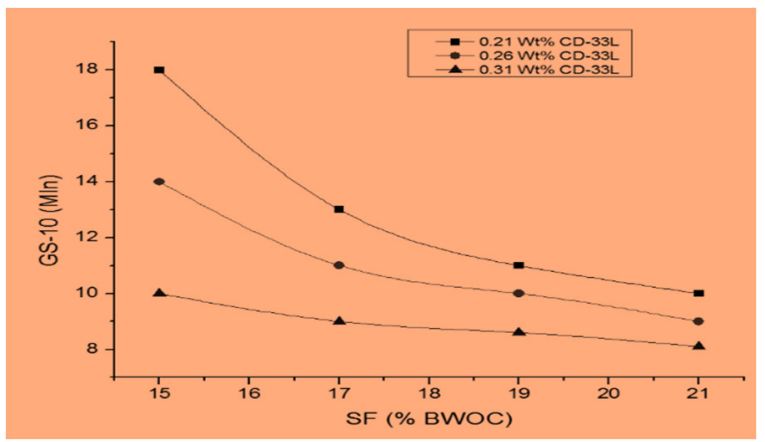

FIG. 5. EFFECTS OF SF AND DISPERSANT ON 10 GS-10 MIN OF 13 PPG SLURRY Mehran University Research Journal of Engineering and Technology, Vol. 39, No. 3, July 2020 [p-ISSN: 0254-7821, e-ISSN: 2413-7219] 
(15-21) \%BWOC, the GS of slurry was decreased 18$10 \mathrm{lb} / 100 \mathrm{ft}^{2}$. Due to the internal friction of cement inter particles spacing increased as strength for GS-10 min; same trend was observed with silica fume concentrations and dispersants.

Thereby the dispersant concentration was increased from (0.26-0.31) \% Wt it was noticed that dispersant concentration decreased the GS at 10 minutes due to increase internal grain spacing. The reduction in GS was due to dispersed effect of cement slurry, because the cement particles not much attract to each other that causes reduction in GS-10 min readings. At $0.21 \% \mathrm{Wt}$ dispersant, the cement slurry has preferable strength for 10 -minutes at the appropriate condition with $\% \mathrm{Wt}$ $(15,17,19$ and 21) silica fume as shown in Fig. 5.

\subsection{Combined Effect of Sf, Dispersion and Fluid Loss Control on Cement Rheology of 13 Ppg Slurry}

The cement slurry of 13 ppg was prepared, with combination of additives such as silica fume $\% \mathrm{BWOC}$ $(15,17,19$ and 21$)$, dispersants $\% \mathrm{Wt}(0.21, .0 .26$ and 0.31 ) and fluid loss control additive \%Wt 1. Rheological properties (PV, YP, GS (GS-10 Sec and GS-10 Min)) of the above slurry were measured at $123^{\circ} \mathrm{C}$.

\subsection{Combined Additive Effects on Plastic Viscosity of 13 ppg Slurry}

In this section PV of 13 ppg cement slurry was measured to study the effect of combination of additives, (SF, dispersant and fluid loss control).

Fig. 6 depicts that PV increased with the increasing of silica fume and fluid loss control additive. The cause of the improvements of PV is due to the addition of FL-66L which is a water soluble additive. The fluid loss additive is viscosifier agent that increases the viscosity of slurries. It filled the pore space of cement particles and reduced the permeability. The addition of $1 \% \mathrm{Wt}$ of fluid loss additive has the same effect on the PV for all cement slurries that were used in this work $(15,17,19$ and 21) silica fume \%BWOC.

\subsection{Combined Additives Effects on Yield Point of 13 ppg Slurry}

In this section YP of 13 ppg cement slurry were measured by combination of additives, SF, dispersant and fluid loss control additive.

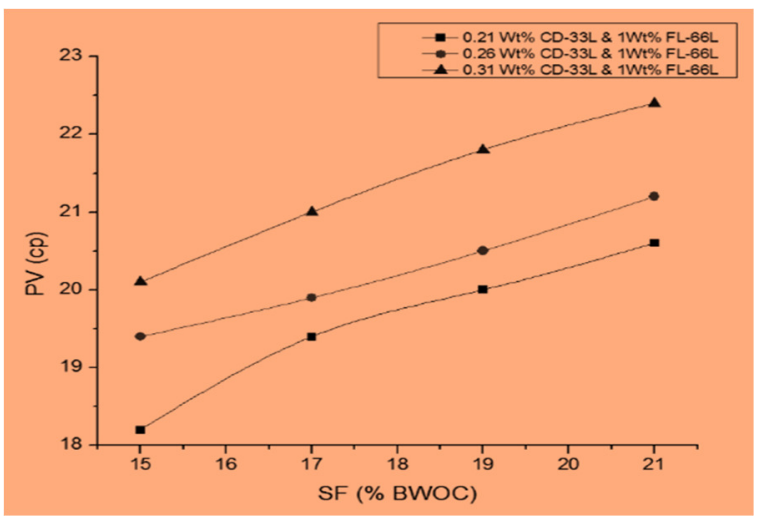

FIG. 6. COMBINED ADDITIVE EFFECTS ON PV OF 13 PPG SLURRY

YP of 13 ppg cement slurries are show in Fig. 7. Fig. 7 shows that the YP readings were increasing with the addition of $1 \% \mathrm{Wt}$ fluid loss control additive in cement slurry, since the fluid loss control additive (FL-66L) is a water soluble additive and it is highly compatible, to combine with other additives. The water soluble additive increases the rheology of the continuous phase of cement slurry.

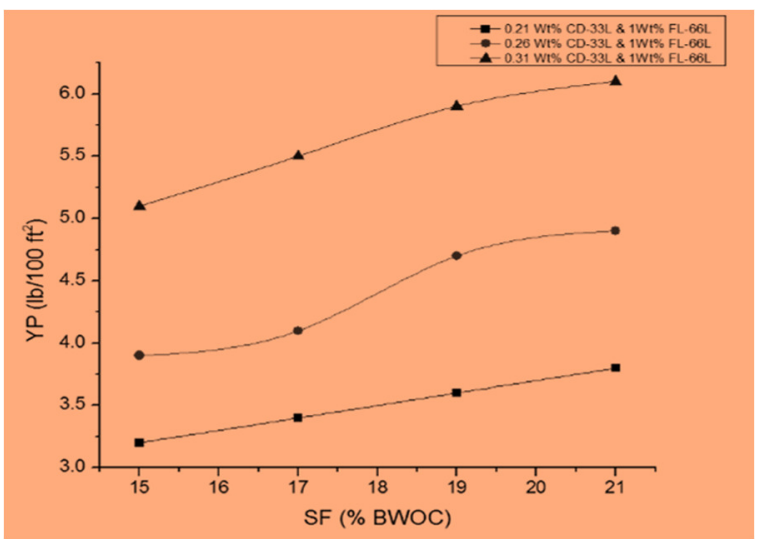

FIG. 7. COMBINED ADDITIVE EFFECTS ON YP OF 13 PPG

The fluid loss may also absorb into the cement grain surface, thus reducing the size of the pores. Moreover, the interaction among the dispersant, fluid loss and silica fume concentrations cause an increase in YP. It was noticed that addition of $1 \% \mathrm{Wt}$ fluid loss control additive has the same effect on YP for all slurries that were used in this work $(15,17,19$ and 21) \%BWOC silica fume. 


\subsection{Combined Additive Effects on Gel Strength (GS-10 Sec) of 13 ppg Slurry}

GS (GS-10 Sec) reading of 13 ppg cement slurry were measured the value shows the effects of four different concentration of silica fume $(15,17,19$ and 21) $\%$ BWOC, combined with three different concentrations of dispersants \%Wt $(0.21,0.26$ and 0.31 ) and fluid loss control additives $1 \% \mathrm{Wt}$ on the GS

readings of 13 ppg cement slurry.

Fig. 8 shows that the additives of $1 \%$ Wt of fluid loss control caused an increase in GS (GS-10 sec) of the cement slurry for all concentration of silica fume and dispersant concentration. Further it is noticed that the maximum strength $13.1 \mathrm{lb} / 100 \mathrm{ft}^{2}$ at the combination of silica fume $21 \% \mathrm{BWOC}$ and dispersant $0.31 \% \mathrm{Wt} \%$ with $1 \% \mathrm{Wt}$ fluid loss control additives.

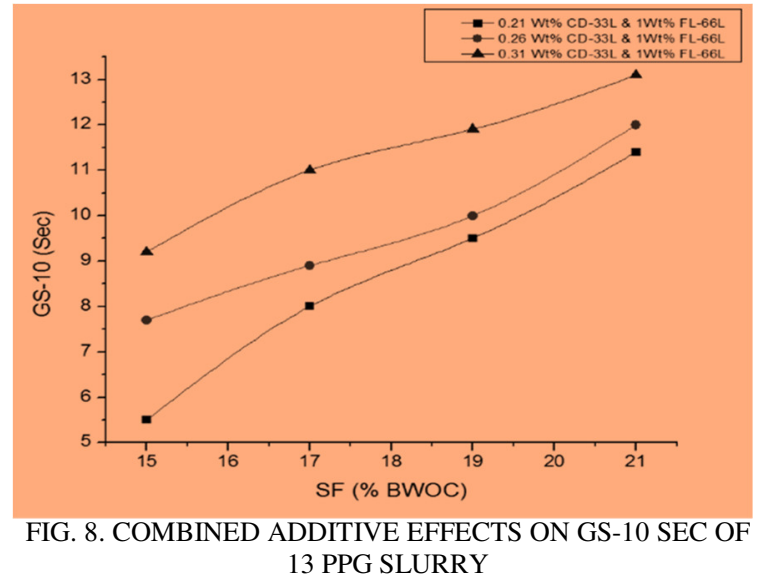

\subsection{Combined Additive Effects on Gel Strength (GS-10 Min) of 13 ppg Slurry}

The GS-10 min of 13 ppg cement slurry was prepared with $(15,17,19$ and 21$) \%$ BWOC silica fume with combination of dispersant $\% \mathrm{Wt}(0.21,0.26$, and 0.31$)$ and fluid loss control additive $1 \% \mathrm{Wt}$.

Illustrates in Fig. 9 that the 10-minutes GS of slurry increased from 13-24.7 lb/100 $\mathrm{ft}^{2}$ by increasing silica fume and dispersant with combination of $1 \% \mathrm{Wt}$ of fluid loss in all slurries were prepared. Further it is concluded that concentration of dispersant $0.31 \% \mathrm{Wt}$, SF $21 \%$ BWOC and fluid loss control $1 \% \mathrm{Wt}$ shows optimum reading of GS-10 Min that is $24.7 \mathrm{lb} / 100 \mathrm{ft}^{2}$.

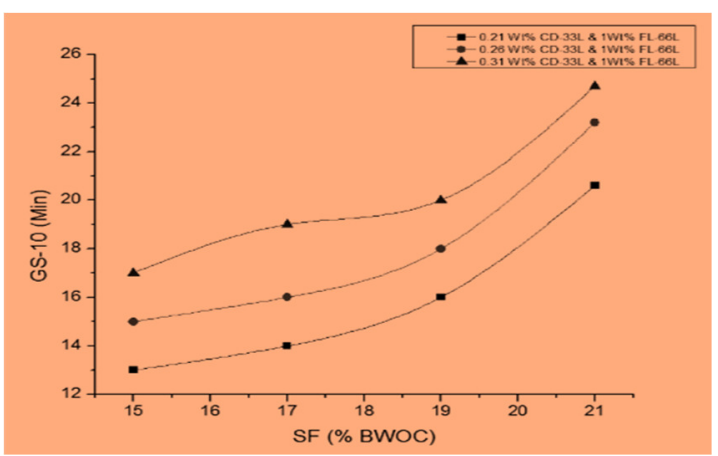

FIG. 9. COMBINED ADDITIVE EFFECTS ON GS-10 MIN OF 13 PPG SLURRY

\section{CONCLUSIONS}

A study was conducted to understand the rheological properties by using different additives schemes to improve cement pump ability. The main conclusions in this paper are as follows.

(i) Silica fume works as a water absorber usually has a strong tendency to absorb water in the cement slurries at dispersant concentration $0.21 \% \mathrm{Wt}$ to improved rheology in 13 ppg cement densities.

(ii) It is observed that using constant dispersant concentration at $0.21 \% \mathrm{Wt}$ the GS of cement slurry was decreased from $8-5.5 \mathrm{lb} / 100 \mathrm{ft}^{2}$ by increasing silica fume concentration.

(iii) It is further noticed that the increasing concentration of dispersant the GS at 10 seconds of slurry was decreased using 0.26 and $0.31 \% \mathrm{Wt}$ dispersant in cement slurry. Similarly, GS-10 min readings. At $0.21 \% \mathrm{Wt}$ dispersant, the cement slurry has preferable strength for 10-minutes at the appropriate condition was observed.

(iv) It is also observed that HTHP subsurface well. In addition, to $1 \% \mathrm{Wt}$ fluid loss control additives to the cement density $13 \mathrm{ppg}$ cause to improve in rheological properties (PV, YP); from 15.8-22.4 PV and YP 4.9-6.1, GS-10 sec, $13.1 \mathrm{lb} / 100 \mathrm{ft}^{2}$ and (GS-10 min) from 13-24.7 $\quad \mathrm{b} / 100 \quad \mathrm{ft}^{2}$. Furthermore, this increment of fluid loss control additive improved in cement slurry 13 ppg and prevented form regression in HPHT.

\section{ACKNOWLEDGEMENTS}

The authors are highly grateful to acknowledge and support from Universti Teknologi Petronas, Malaysia, Mehran University Research Journal of Engineering and Technology, Vol. 39, No. 3, July 2020 [p-ISSN: 0254-7821, e-ISSN: 2413-7219] 
for providing all important technical requirements to conduct this research. Authors are also thankful to the Institute of Petroleum \& Natural Gas Engineering, Mehran University of Engineering \& Technology, Jamshoro, Pakistan.

\section{REFERENCES}

[1] Nnamdi, C.A, "Experimental Study of the Effect of Drilling Fluid Contamination on the Integrity of Cement Formation Interface", Master Thesis, Louisana State University, 2012.

[2] Memon, K.R., "Laboratory Investigation on Performnce of Cement Using Different Additive Scheme Based on Mechanical Properties", Master Thesis, Unversiti Teknologi Malaysia, 2014.

[3] Erik, B.N, "Well Cementing", Volume 1, pp,1-5, Elsevier Science, 1990.

[4] Garnier, A., Fraboulet, B.J.M., and Bois, A., "Characterization of Cement Systems to Ensure Cement Sheath Integrity", Offshore Technology Conference, Houston, Texas, USA, 2007.

[5] Calvert, D., and Smith, D., "API Oilwell Cementing Practices", Offshore Technology Conference, 1990.

[6] García-Gutiérrez, A., Espinosa-Paredes, G., and Amaro-Espejo, G., "Effect of Variable Rheological Properties of Drilling Muds and Cements on the Temperature Distribution in Geothermal Wells", Prceeding World Geothermal Congress, Antalya, Turkey, 2005.

[7] Olha Sukhoboka "Drilling Fluid Rheology Under High Pressure High Temperature Conditions and its Impact on the rate of Penetration" SPE Conference Paper.2017.

[8] Shahriar, A., and Nehdi, M., "Investigation on Rheology of Oil Well Cement Slurries", The University of Western Ontario, 2011.

[9] Anisimova A.V. Tolkacheve G.M. Kozlov A.S. "Influenceofthermobaric conditions on rheological properties of magnesian oil-well cement slurries", SPE ID:OIJ-2018-01-048051-RU

[10] Guillot, D., " Rheology of Well Cement
Slurries", Developments in Petroleum Science, Vol. 28, pp. 4-1-4-37, 1990.

[11] Ravi, K., McMechan, D., Reddy, B., and Crook, R., "A Comparative Study of Mechanical Properties of Density-Reduced Cement Compositions", SPE Annual Technical Conference and Exhibition,Houston, Texas, 2004.

[12] Ravi, K., and Sutton, D., "New Rheological Correlation for Cement Slurries as a Function of Temperature", SPE Annual Technical Conference and Exhibition, New Orleans, Louisiana, 1990.

[13] Hodne, H., Saasen, A., and Strand, S., "Rheological Properties of High Temperature Oil Well Cement Slurries", Annual Transactions-Nordic Rheology Society, Vol. 8, pp. 31-38, 2001.

[14] Pedam, S.K., "Determining Strength Parameters of Oil Well Cement", University of Texas, Austin, 2007.

[15] Labibzadeh, M. "Assessment of the Early Age Tensile Strength of the Oilfield Class G Cement under Effects of the Changes in Down-Hole Pressure and Temperature", Trends in Applied Sciences Research, Vol. 5, pp. 165-176, 2010.

[16] Svavarsson, H., and Wallevik, O.,"Geothermal Well Cementing the Effect of Temperature and Time on Workability Loss", Annual Transactions of the Nordic Rheology Society, Vol. 12, 2004.

[17] Miranda, C., Toledo, F.R., Fairbairn, E., Thaumaturgo, C., Vargas, A., and Oliveira, G., "New Design of High-Performance Cement Systems for Zonal Isolation: Influence on Porosity, Rheological Parameters, and Chemical and Mechanical Resistance", SPE Latin American and Caribbean Petroleum Engineering Conference, 2010.

[18] Vijin, P., "Improved Cement Formulation for Well Abandonment", Offshore Mediterranean Conference, Texas, 2001.

[19] "American Petroleum Institute Recommended Practice for Testing Well Cements", 10B Washington, DC USA, 2010. [20] Michaux, M., Oberste-Padtberg, R., and Mehran University Research Journal of Engineering and Technology, Vol. 39, No. 3, July 2020 [p-ISSN: 0254-7821, e-ISSN: 2413-7219] 
Defosse, C., "Oil Well Cement Slurries-II. Adsorption Behaviour of Dispersants", Cement and Concrete Research, Vol. 16, pp. 921-930, 1986.

[21] Saasen, A., Rafoss, E., and Behzadi, A., "Experimental Investigation of Rheology and Thickening Time of Class-G Oil Well Cement Slurries Containing Glycerin", Cement and Concrete Research, Vol. 21, pp. 911-916, 1991.

[22] Chougnet, A., Audibert-Hayet, A., Lecolier, E., Moan, M., Guichard, B., and Mazard, C., "Polymer Powder/Cement Composites for Oil and Gas Wells", SPE Annual Technical Conference and Exhibition, San Antonio, USA, 2006.
[23] Noik, C., and Rivereau, A., "Oilwell Cement Durability", SPE Annual Technical Conference and Exhibition, Houston, Texas, 1999.

[24] Kelessidis M.V.C., Fraim, M., Fardis, E., Karakosta, G., Diamantopoulos, P., Arkoudeas, S., and El-Hardalo, L.L., "Comprehensive Assessment of Additive and Class-G Cement Properties Affecting Rheology, Fluid Loss, Setting Time and Long Term Characteristics of Elastic Cements", SPE/EAGE European Unconventional Resources Conference and Exhibition, Vienna, Austria , 25-27 February, 2014. 